\title{
Laurin-Sandrow syndrome
}

INSERM

\section{Source}

INSERM. (1999). Orphanet: an online rare disease and orphan drug data base. LaurinSandrow syndrome. ORPHA:2378

Laurin-Sandrow syndrome (LSS) is characterised by complete polysyndactyly of the hands, mirror feet and nose anomalies (hypoplasia of the nasal alae and short columella), often associated with ulnar and/or fibular duplication (and sometimes tibial agenesis). It has been described in less than 20 cases. Some cases with the same clinical signs but without nasal defects have also been reported, and may represent the same entity. The etiology of LSS is unknown. Different modes of inheritance have been suggested. 